Muhammad Ali Javed, Elmar Baumhögger, Jadran Vrabec

\title{
Thermodynamic speed of sound of xenon
}

Journal article | Accepted manuscript (Postprint)

This version is available at https://doi.org/10.14279/depositonce-9397

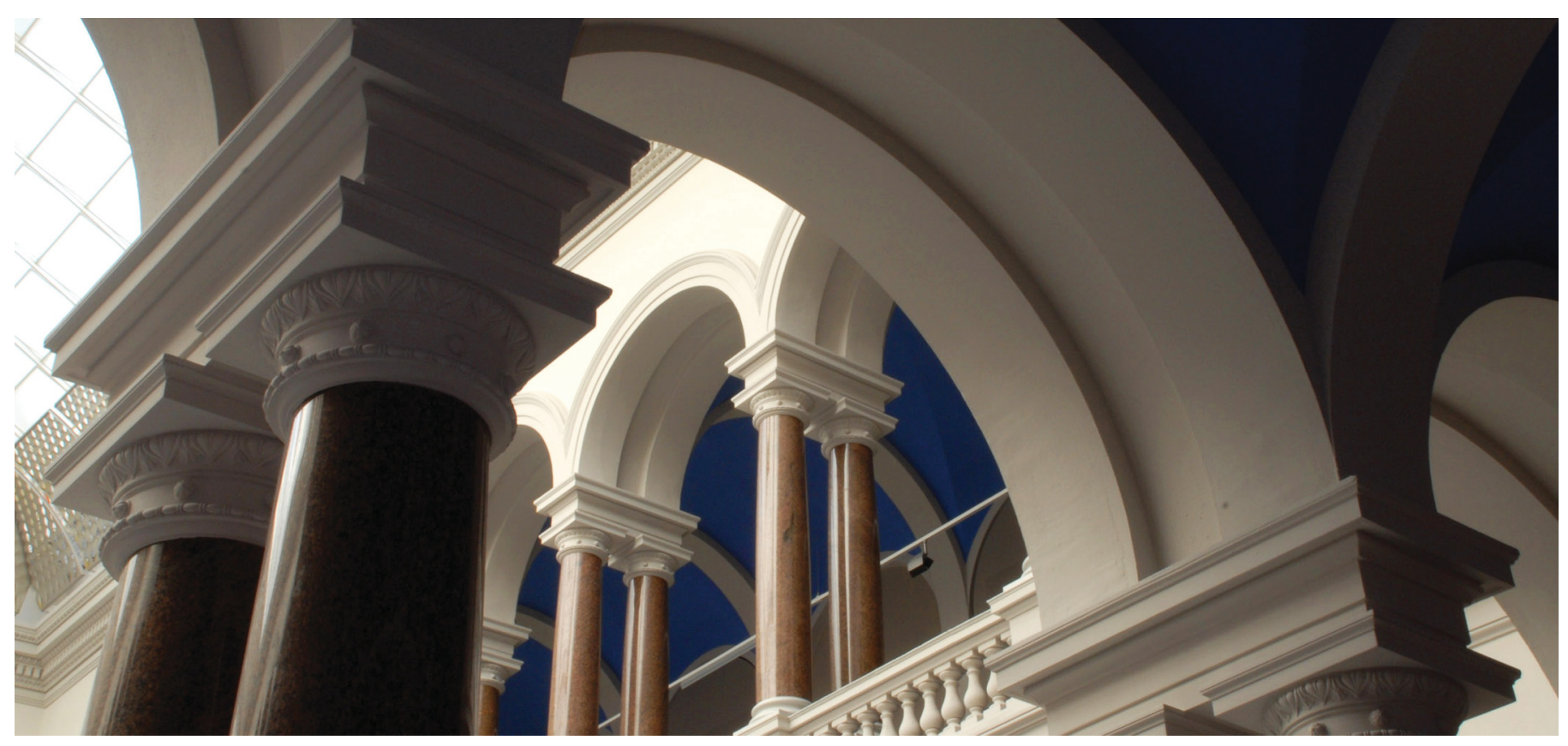

Javed, M. A., Baumhögger, E., \& Vrabec, J. (2019). Thermodynamic speed of sound of xenon. The Journal of Chemical Thermodynamics, 141, 105933. https://doi.org/10.1016/j.jct.2019.105933 
Accepted manuscript of: Javed, M. A., Baumhögger, E., \& Vrabec, J. (2020). Thermodynamic speed of sound of xenon. The Journal of Chemical Thermodynamics, 141, 105933.

https://doi.org/10.1016/j.jct.2019.105933

(C) 2019 This manuscript version is made available under the CC-BY-NC-ND 4.0 license https://creativecommons.org/licenses/by-nc-nd/4.0/

\title{
Thermodynamic speed of sound of xenon
}

\author{
Muhammad Ali Javed ${ }^{\mathrm{a}}$, Elmar Baumhögger ${ }^{\mathrm{b}}$, Jadran Vrabec $^{\mathrm{a}, *}$ \\ ${ }^{a}$ Thermodynamics and Process Engineering, Technical University of Berlin, 10623 Berlin, \\ Germany \\ ${ }^{b}$ Thermodynamics and Energy Technology, University of Paderborn, 33098 Paderborn, \\ Germany
}

\begin{abstract}
Thermodynamic speed of sound data are an important basis for the development of Helmholtz energy equations of state because of their thermal and caloric nature. Moreover, they can be measured rapidly and with a high accuracy. Xenon is sampled with the pulse-echo technique to provide the speed of sound data covering a temperature range from $217 \mathrm{~K}$ to $500 \mathrm{~K}$ with a pressure of up to $100 \mathrm{MPa}$. The measurement cell's path length is calibrated with water and validated with the reference equation of state by Wagner and $\operatorname{Pru} \beta$. At a confidence level of $95 \%(k=2)$, the data have an overall expanded uncertainty of up to $0.17 \%$ near the critical point and less than $0.1 \%$ in the liquid and supercritical regions. The results are in good agreement with the Helmholtz energy equation of state by Lemmon and Span with a maximum deviation of up to $1.1 \%$. The present data are also used to optimize the parameters of the Lennard-Jones potential and its truncated and shifted form for xenon. This parameterization leads to a convincingly better performance for the speed of sound calculation, but the representation of other properties, like the vaporliquid two phase region, is significantly deteriorated.
\end{abstract}

Keywords: Xenon; Water; Speed of sound; Pulse-echo technique;

Lennard-Jones potential.

\footnotetext{
* Corresponding author

Email address: vrabec@tu-berlin.de (Jadran Vrabec)
} 


\section{Introduction}

Xenon is a dense, colorless, odorless and tasteless noble gas that is present at about 90 ppb in earth's atmosphere. 3. Although it is chemically inert and nontoxic, xenon can form strongly oxidizing agents and highly toxic compounds, like 5 xenon hexafluoroplatinate. Naturally, xenon exists in seven stable isotopes, two long-lived radioactive isotopes and more than 40 unstable isotopes that undergo radioactive decay. 4. Under ambient conditions, its density $\left(5.761 \mathrm{~kg} \mathrm{~m}^{-3}\right)$ is approximately 4.5 times the density of earth's atmosphere at sea level. In the liquid state, it has a density of up to $3100 \mathrm{~kg} \mathrm{~m}^{-3}$ with a maximum at the triple 10 point. [5]

The current global production of xenon is about 53,000 $\mathrm{kg}$ per year and its demand increases steadily. [6] However, the supply is not a big concern because the atmospheric reserves are larger than 2 billion tonnes. [7] Xenon is commercially obtained as a byproduct during the separation of oxygen and nitrogen from air, further purification is carried out by additional fractional distillation. 8. As xenon is a rare gas, it is relatively expensive to extract it from the atmosphere. [9]

Because of its distinct nature and non-reactive characteristics, xenon has numerous applications. About $15 \%$ of its total production is used as an anesthetic. In the liquid state, it is an excellent solvent for hydrocarbons, biological compounds and even water.10 Recently, liquid xenon detectors were used for the search of dark matter. 11] Moreover, it also serves as a fuel in xenon ion repulsion systems (XIPS), which are implemented in satellites and spacecraft. 12. Other applications are in illumination and optics, 13, 14] nuclear magnetic resonance (NMR) spectroscopy [15] and microelectromechanical systems. [16]

Because of the expanding demand for xenon in different sectors, accurate thermodynamic data are essential to optimize its supply and use. The speed of sound is an important thermodynamic property to develop highly precise Helmholtz energy equations of state and simulation models.[17, 18, 19] Currently, an insufficient amount of experimental speed of sound data of good accuracy is available for xenon. 
Measurements of the thermodynamic speed of sound of xenon were described in seven publications, details on their number of data points and covered temperature and pressure ranges are provided in Table 1. However, most data are 40 to 50 years old and most authors measured near the saturation line with a pressure of up to $6.6 \mathrm{MPa}$ 20, 21, 22, 23, 24], cf. Figure 1. Pitaevskaya et al. 25] and Vidal et al. 26, 27] have reported the speed of sound data in the supercritical region, but their assessment shows that the data by Pitaevskaya et al. 25] have a maximum deviation of more than $6 \%$ from the Helmholtz energy equation of state by Lemmon and Span 2] that is recommended by the National Institute of Standards and Technology (NIST). Vidal et al. 26] have measured nine state points along a single isotherm of $298 \mathrm{~K}$ and their data deviate by up to $8 \%$ from that equation of state. For the pressure range between 6.6 $\mathrm{MPa}$ and $40 \mathrm{MPa}$, no experimental data were available, cf. Figure 1.

In the present work, the speed of sound of xenon was measured by implementing a double path length pulse-echo technique for liquid and supercritical states. A temperature range from $217 \mathrm{~K}$ to $500 \mathrm{~K}$ with a pressure of up to 100 MPa was covered. The results have a maximum expanded uncertainty of $0.17 \%$ at a confidence level of $95 \%(k=2)$ for the entire measurement range. Moreover, a comprehensive comparison of the present data with the literature data and the equation of state by Lemmon and Span was carried out. The present data are in good agreement with that equation of state and have a maximum deviation of $1.1 \%$. The existing equation of state should be improved on the basis of the present data. Furthermore, the parameters of the Lennard-Jones (LJ) potential and its truncated and shifted (LJTS) form were optimized to the present data.

\section{Experimental}

\subsection{Materials}

For calibration of the apparatus, water was purchased from Merck with a mass fraction purity of 0.999 . It was degassed prior to the measurements by 


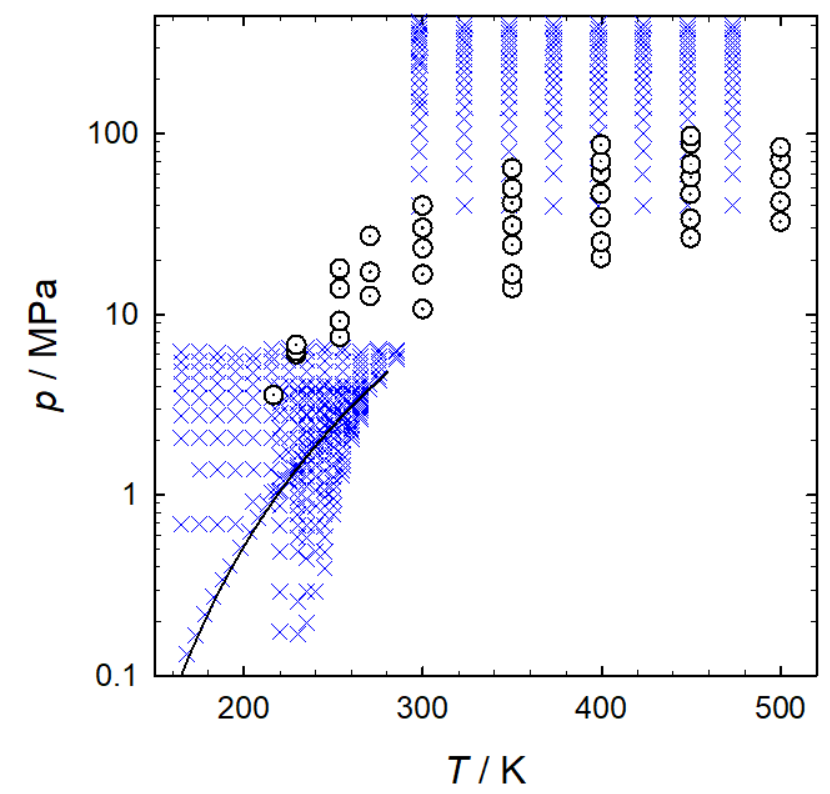

Figure 1: State points for which the speed of sound was measured: present work $\odot$, experimental literature data $\times$. The solid line is the vapor pressure curve.

Table 1: Experimental speed of sound data for xenon from the literature, where $N$ is the number of measured data points, $T_{\min }-T_{\max }$ the temperature range and $p_{\max }$ the maximum pressure.

\begin{tabular}{|c|c|c|c|c|c|}
\hline author & year & $N$ & $T_{\min }-T_{\max } / \mathrm{K}$ & $p_{\max } / \mathrm{MPa}$ & $u_{w} / \mathrm{m} \mathrm{s}^{-1}$ \\
\hline Blagoi et al. 20 & 1967 & 23 & $162-270$ & vapor pressure & 0.5 \\
\hline Aziz et al. 21 & 1967 & 71 & $162-272$ & vapor pressure & 0.5 \\
\hline Lim et al. 22 & 1968 & 116 & $165-285$ & 6.6 & 0.1 \\
\hline Pitaevskaya et al. 25] & 1975 & 152 & $298-473$ & 400 & 6 \\
\hline Vidal et al. 26, 27. & 1979 & 9 & 298 & 419 & 0.2 \\
\hline Baidakov et al. 24 & 1985 & 159 & $220-270$ & 4 & 0.1 \\
\hline Hurly et al. 23 & 1997 & 232 & $210-400$ & vapor pressure & 0.5 \\
\hline
\end{tabular}


Table 2: Suppliers and mass-fraction purity $y$ of the samples, as provided by the suppliers.

\begin{tabular}{ccccc}
\hline chemical name & CAS number & source & $y$ & purification method \\
\hline water & $7732-18-5$ & Merck & 0.999 & none \\
xenon & $7440-63-3$ & Air Liquide & 0.995 & none \\
\hline
\end{tabular}

keeping it under vacuum for almost $24 \mathrm{~h}$. Xenon was provided by Air Liquide in a metal flask with a pressure of about $5.3 \mathrm{MPa}$ at ambient temperature. Its mass fractional purity was 0.995 and contained impurities below $78 \mathrm{ppm}$, which included traces of argon, krypton, nitrogen, oxygen, hydrocarbons and water. It was used as a sample without further treatment, cf. Table 2.

\subsection{Apparatus layout}

A schematic of the speed of sound measurement apparatus employed in the present work is shown in Figure 2. The preeminent part of this rig was an acoustic cell, fabricated from a stainless steel, type 1.4571. It consisted of four segments, where the acoustic transducer was placed in the center, surrounded by two metallic reflectors at different distances, cf. Figure 3 . The cell was located in a cylindrical pressure vessel of $50 \mathrm{~mm}$ inner diameter and $25 \mathrm{~mm}$ of wall thickness, fabricated from a highly tensile steel, type 1.4462. It had a volume of almost $200 \mathrm{~cm}^{3}$ and could detain a pressure of up to $100 \mathrm{MPa}$. To achieve and maintain elevated temperatures, the pressure vessel was surrounded

75 by three copper jackets, equipped with three electric resistance heaters. For low temperature measurements, a thermostat (Huber Unistat 825w) with ethanol as a heat transfer fluid was employed. This alcohol was circulated through a stainless steel pipe which was mounted to the inner jacket. The sample fluid (xenon) pressure was specified with a high pressure hand pump (HIP 50-5.75-30) so with a $20 \mathrm{~cm}^{3}$ cylinder volume and $200 \mathrm{MPa}$ of maximum operating pressure. For technical reasons, the present measurements were limited to $100 \mathrm{MPa}$.

The sample temperature was measured with a platinum resistance thermometer PT-25 (type 162CE Rosemount) located in the wall of the pressure vessel, cf. Figure 2. Moreover, to check whether the temperature was con- 


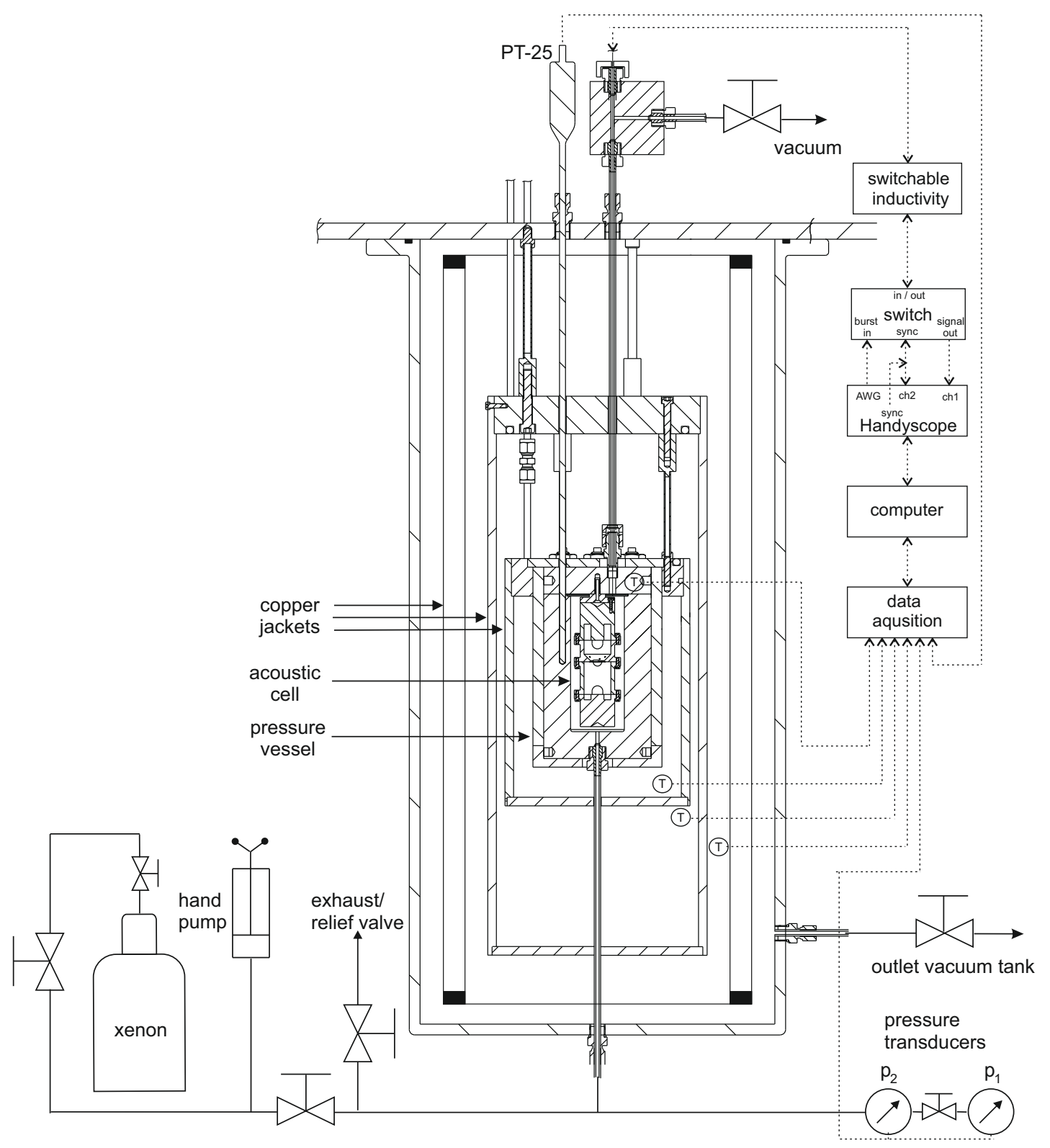

Figure 2: Schematic of the employed speed of sound measurement apparatus, showing that the acoustic sensor was placed inside the pressure vessel, surrounded by copper jackets. Signal generation and detection was done by an oscilloscope (Handyscope HS5). The experimental conditions were monitored and controlled with a computer that also served for data acquisition. 
stant throughout the sample fluid, two additional PT-100 thermometers were installed at the top of the pressure container. Furthermore, for a better accuracy of pressure measurements, two transducers with different operating ranges, i.e. Keller-PAA-33X for $p<10 \mathrm{MPa}$ and Keller-PAA-33X for $p<100 \mathrm{MPa}$, were installed at the bottom pipe, cf. Figure 2 .

\subsection{Measurement principle}

An $8 \mathrm{MHz}$, x-cut piezoelectric crystal disk of $15 \mathrm{~mm}$ diameter with $10 \mathrm{~mm}$ gold plated electrodes was used as an acoustic transducer. It was alternately connected to an arbitrary signal generator and an oscilloscope by a fast radio switch, where a Handyscope HS5 served as burst generator and oscilloscope, cf. Figure 2, To compensate the quartz and cable capacity, a step switch with selectable inductivity was positioned in the electric connection. Burst generator and oscilloscope were controlled and read out by a computer.

To measure the speed of sound, a sinusoidal burst signal of eight periods with an amplitude of $10 \mathrm{~V}$ was generated to excite the quartz. Consequently, two sound waves propagated trough a sample fluid and, after reflection, were received by the quartz at different time instances, cf. Figure 3 . The speed of sound $w$ was measured as

$$
w=\frac{2 \Delta L}{\Delta t}
$$

where $\Delta L$ is the path length difference of the two reflectors and $\Delta t$ the delay in the time of flight caused by $2 \Delta L$. In equation (1), diffraction effects were neglected because the according corrections would amount to less than $0.01 \%$ of the measured time difference. [28, 29] Moreover, by calculating the difference in transient time, diffraction and electronic delay errors should be suppressed by cancellation. 28 ]

\subsubsection{Path length calibration}

105

The acoustic path length difference $\Delta L\left(T_{0}, p_{0}\right)=9.9815 \mathrm{~mm}$ was calibrated with water at the state point of $T_{0}=300 \mathrm{~K}$ and $p_{0}=1.29 \mathrm{MPa}$. Water was chosen as a reference fluid because of the availability of the highly precise 


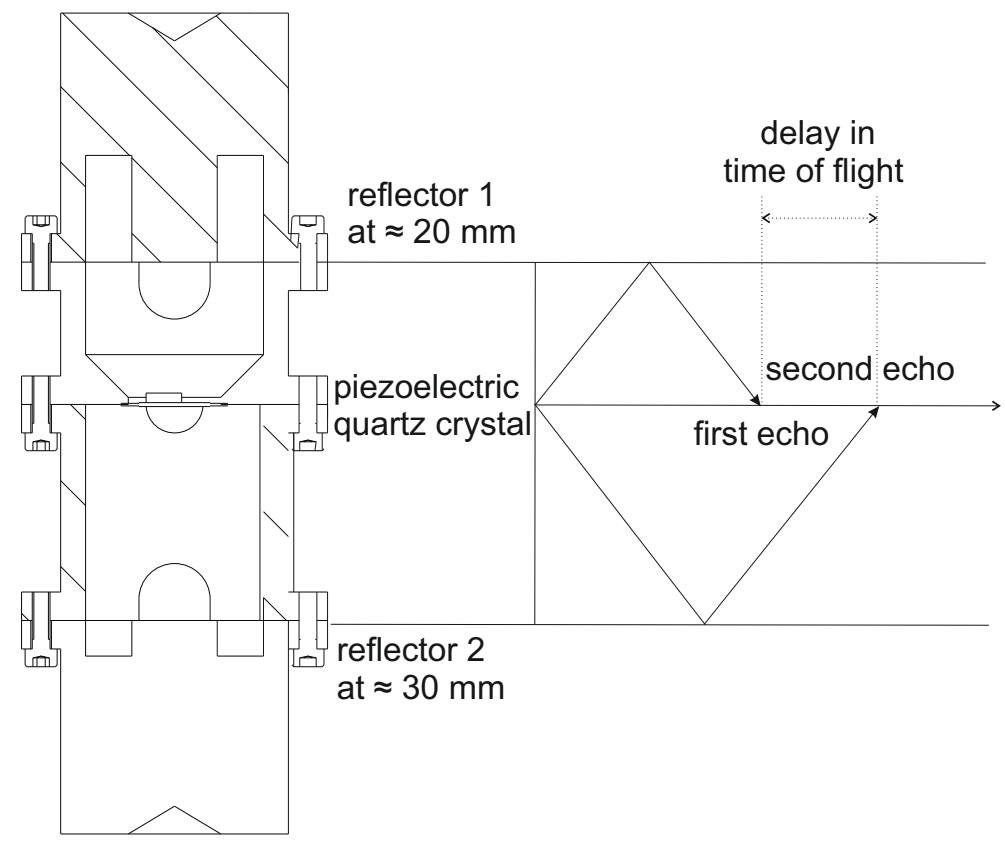

Figure 3: Working principle of the acoustic cell based on the pulse-echo technique. A delay in time of flight $\Delta t$ was caused by different distances between the quartz crystal and the two reflectors. 
reference quality equation of state by Wagner and $\operatorname{Pru} \beta[1]$ with an uncertainty of $0.005 \%$ for the speed of sound at the specified state point. Moreover, at ambient temperature, very accurate speed of sound measurements were reported by several authors, 30, 31, 32, 33. which were used for validation of the present calibration.

The variation of the path length difference due to thermal expansion and pressure compression was considered by $[17]$

$$
\Delta L(T, p)=\Delta L\left(T_{0}, p_{0}\right)\left[1+\bar{\alpha}-\frac{1}{E}(1-2 \nu)\left(p-p_{0}\right)\right] .
$$

Therein, $\nu=0.3$ is the Poisson number of the steel which was provided by its supplier (Thyssen-Krupp Materials International) and $\bar{\alpha}$ is the integral thermal expansion coefficient of the stainless steel 1.4571 between the temperatures $T_{0}$ and $T$

$\bar{\alpha}=\left[n_{0}\left(T-T_{0}\right)+\frac{n_{1}}{2}\left(T^{2}-T_{0}^{2}\right)+\frac{n_{2}}{3}\left(T^{3}-T_{0}^{3}\right)+\frac{n_{3}}{4}\left(T^{4}-T_{0}^{4}\right)+\frac{n_{4}}{5}\left(T^{5}-T_{0}^{5}\right)\right]$,

where $n_{0}=4.7341 \cdot 10^{-6} \mathrm{~K}^{-1}, n_{1}=7.1518 \cdot 10^{-8} \mathrm{~K}^{-2}, n_{2}=-1.5273 \cdot 10^{-10} \mathrm{~K}^{-3}$, $n_{3}=1.5864 \cdot 10^{-13} \mathrm{~K}^{-4}$ and $n_{4}=-6.1342 \cdot 10^{-17} \mathrm{~K}^{-5}$. Since the modulus of elasticity $E$ is temperature dependent too, it was determined with a first order polynomial

$$
E=a+b(T),
$$

where $a=219711.07 \mathrm{MPa}^{-1}$ and $b=-79.8 \mathrm{~K}^{-1} \mathrm{MPa}^{-1}$. A comparison of the present calibration measurements with the equation of state by Wagner 115 and $\operatorname{Pru} \beta$, , along with the experimental data by Lin and Trusler with an uncertainty of $0.04 \%$ [30] and $\mathrm{Al}$ Ghafri et al. 34 with an uncertainty of $0.03 \%$, is presented in Figure 4. It is evident that the present results are in very good agreement with the equation of state, even at elevated pressures. Except for a single state point, the deviation is almost within $0.02 \%$ for the entire set of calibration measurements. The maximum deviation is $0.05 \%$ at $400 \mathrm{~K}$ and 1.3 $\mathrm{MPa}$, but it should be noted that at high temperature and low pressure, the literature data are less accurate too and the equation of state is $0.1 \%$ uncertain in this region. 


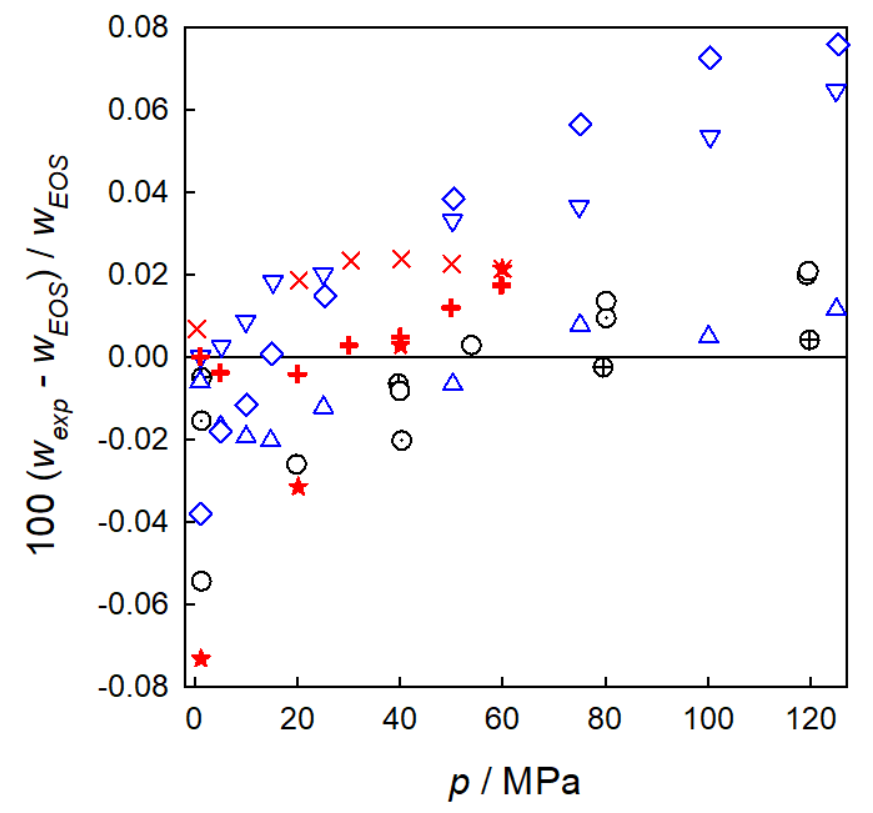

Figure 4: Comparison of the calibration measurements with the Helmholtz energy equation of state by Wagner and Pru $\beta$ ]. Experimental data: this work, $300 \mathrm{~K} \odot, 350 \mathrm{~K} \oplus, 400 \mathrm{~K} \bigcirc$; Lin and Trusler 30, 303 K $\triangle, 373 \mathrm{~K} \nabla, 413 \mathrm{~K} \diamond$; Al Ghafri et al.34, $306 \mathrm{~K}+, 358 \mathrm{~K} \times, 421$ $\mathrm{K} \star$. 


\subsection{Time of flight}

125 based software. For a precise measurement, a high resolution in time and amplitude domains was needed, along with minimum ambient noise and distortion. Consequently, signal enhancement was performed by applying a fast Fourier transform (FFT) based band pass filter algorithm of $\pm 20 \%$ around the signal

of flight $\Delta t$ was calculated with the correlation

$$
s\left(\Delta t_{x}\right)=\sum_{t=t_{1}}^{t_{1}+\Delta t_{e}} a(t) \cdot a\left(t+\Delta t_{x}\right),
$$

where $a$ is the amplitude of the signal and $\Delta t_{x}$ ranging from $t_{2}-\left(t_{1}+\Delta t_{e}\right)$ to $\left(t_{2}+\Delta t_{e}\right)-t_{1}$, the definition of these time instances can be seen in Figure 5. The maximum of $s$ indicates the delay in the time of flight between the two 145 echoes.

The accuracy of the time measurement also depends on quality and resemblance of the two signals, which fluctuate with acoustic impedance and attenuation. For xenon, these effects were significant at low pressures, the second echo became wider than the first one and the maximum amplitude within the echo was reached later in the second echo than in the first. This phenomenon was suppressed by applying a brake function as described by Dubberke et al. 35. 


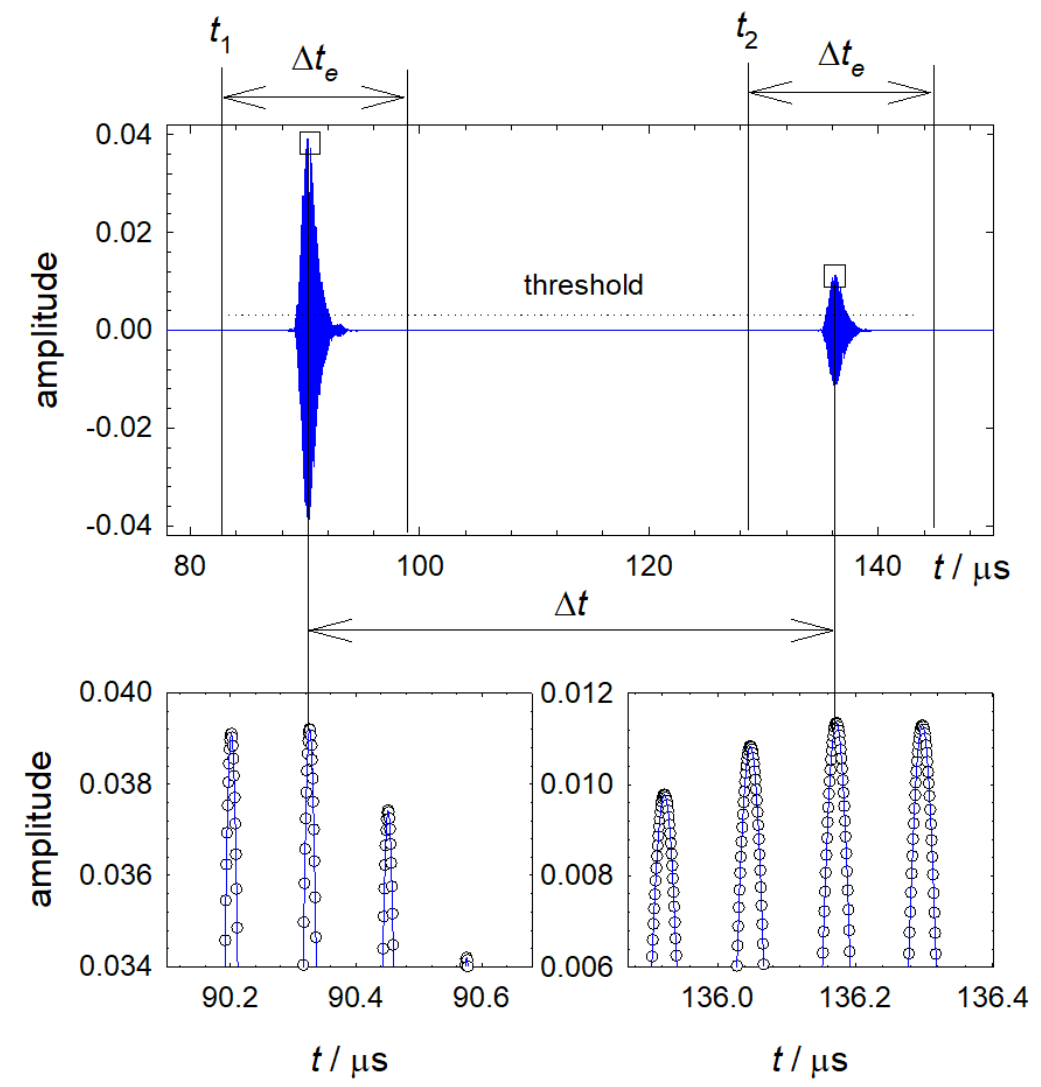

Figure 5: Echoes after applying a band pass filter and zero padding that served for the calculation of the delay in the time of flight $\Delta t$. The lower panel contains magnified views on the echo maxima highlighted in the top panel by squares. 
Xenon was supplied in a gaseous state at the ambient temperature with a pressure of almost 5.3 MPa, which is near its critical region [2]. To fill the fluid into the cell, the pressure vessel was evacuated for about $2 \mathrm{~h}$ and cooled down to a temperature of $216 \mathrm{~K}$. Because of the temperature and pressure gradient, xenon was imbibed into the cell and condensed to the saturated liquid state. After closing the vessel and attaining a constant target temperature and target pressure, the first state point was measured. Subsequently, the fluid was heated in a step-wise manner to a maximum temperature of $500 \mathrm{~K}$ and the hand pump was used to regulate the pressure at each step. It was necessary to keep the pressure below $100 \mathrm{MPa}$ so that some quantity of xenon had to be released. For low pressure measurements, more xenon was discharged at $500 \mathrm{~K}$ and the temperature was again step-wise reduced to the target state points, cf. Figure 6.

\section{Results and discussion}

The speed of sound of xenon was measured at 42 state points and the numerical data with their expanded experimental uncertainties are provided in Table 3.

\subsection{Experimental uncertainty}

The overall expanded uncertainty of the speed of sound $U_{w}$ at a confidence level of $95 \%$ was calculated by considering the standard uncertainty due to temperature $u_{T}$, pressure $u_{p}$, path length calibration $u_{\Delta L}$ and the uncertainty of time measurement $u_{\Delta t}$ for a coverage factor $k=2$

$U_{w}=k\left[\left(\frac{\partial w}{\partial T}\right)_{p, \Delta L, \Delta t}^{2} u_{T}^{2}+\left(\frac{\partial w}{\partial p}\right)_{T, \Delta L, \Delta t}^{2} u_{p}^{2}+\left(\frac{\partial w}{\partial \Delta L}\right)_{T, p, \Delta t}^{2} u_{\Delta L}^{2}+\left(\frac{\partial w}{\partial \Delta t}\right)_{T, p, \Delta L}^{2} u_{\Delta t}^{2}\right]^{1 / 2}$.

Therein, the partial derivatives of the speed of sound with respect to temperature and pressure were calculated with the equation of state by Lemmon and Span 2 for xenon, whereas partial derivatives with respect to length and time were obtained from equation (1). A detailed uncertainty budget for speed 


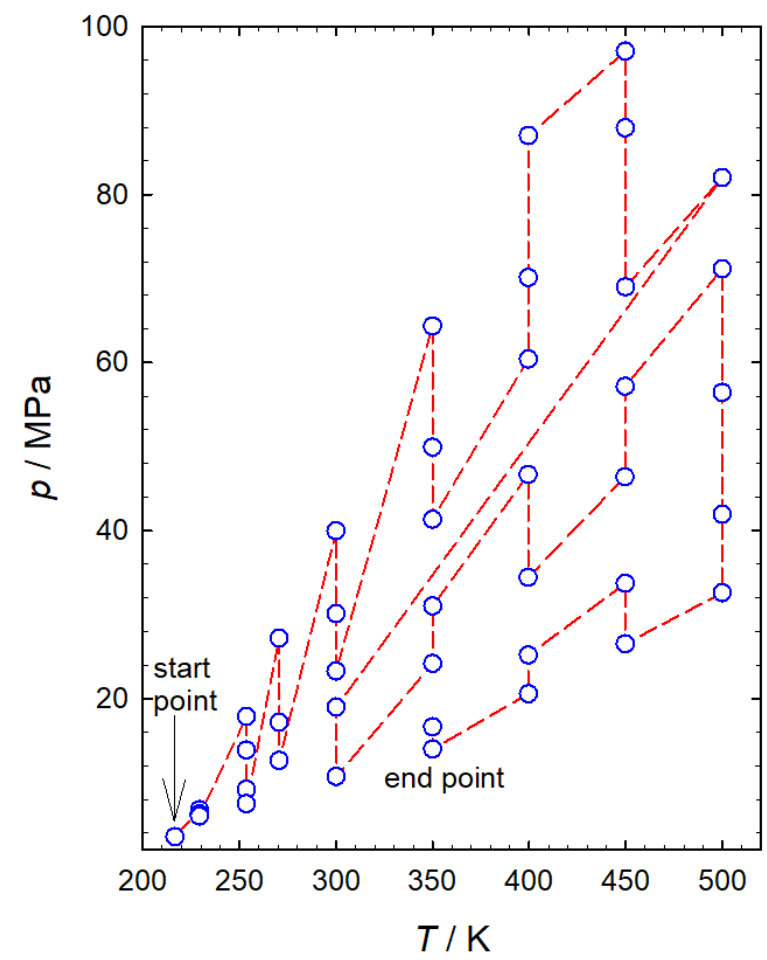

Figure 6: Step-wise approach to measure the target state points. 
Table 3: Speed of sound of xenon with expanded experimental uncertainties at temperature $T$ and pressure $p^{a}$.

\begin{tabular}{|c|c|c|c|c|c|c|c|}
\hline$T / \mathrm{K}$ & $p / \mathrm{MPa}$ & $w / \mathrm{m} \mathrm{s}^{-1}$ & $U_{w} / \mathrm{m} \mathrm{s}^{-1}$ & $T / \mathrm{K}$ & $p / \mathrm{MPa}$ & $w / \mathrm{m} \mathrm{s}^{-1}$ & $U_{w} / \mathrm{m} \mathrm{s}^{-1}$ \\
\hline \multicolumn{4}{|c|}{ liquid state } & 349.96 & 41.32 & 434.6 & 0.3 \\
\hline 216.59 & 3.566 & 504.6 & 0.4 & 349.97 & 49.92 & 473.7 & 0.3 \\
\hline 229.23 & 6.028 & 481.3 & 0.4 & 349.94 & 64.34 & 529.1 & 0.4 \\
\hline 229.24 & 6.276 & 482.8 & 0.4 & 399.61 & 20.58 & 251.5 & 0.2 \\
\hline 229.34 & 6.787 & 485.8 & 0.4 & 399.59 & 25.18 & 284.4 & 0.2 \\
\hline 253.54 & 7.509 & 409.1 & 0.3 & 399.46 & 34.42 & 345.6 & 0.3 \\
\hline 253.55 & 9.198 & 423.7 & 0.3 & 399.44 & 46.68 & 410.7 & 0.3 \\
\hline 253.54 & 13.87 & 457.7 & 0.4 & 399.56 & 60.40 & 468.0 & 0.3 \\
\hline 253.56 & 17.89 & 481.8 & 0.4 & 399.58 & 70.11 & 503.7 & 0.4 \\
\hline 270.49 & 12.65 & 399.3 & 0.4 & 399.57 & 87.00 & 554.9 & 0.4 \\
\hline 270.48 & 17.17 & 434.5 & 0.4 & 449.71 & 26.50 & 277.9 & 0.2 \\
\hline 270.47 & 27.19 & 493.9 & 0.4 & 449.68 & 33.72 & 315.3 & 0.2 \\
\hline \multicolumn{4}{|c|}{ supercritical state } & 449.59 & 46.41 & 377.2 & 0.3 \\
\hline 300.03 & 10.71 & 272.3 & 0.5 & 449.67 & 57.18 & 422.3 & 0.3 \\
\hline 299.99 & 16.65 & 353.0 & 0.4 & 449.85 & 67.82 & 461.1 & 0.3 \\
\hline 299.98 & 23.27 & 408.1 & 0.3 & 449.80 & 87.91 & 525.0 & 0.4 \\
\hline 299.96 & 30.10 & 450.6 & 0.3 & 449.76 & 97.04 & 549.8 & 0.4 \\
\hline 299.92 & 39.95 & 500.0 & 0.4 & 499.90 & 32.59 & 302.3 & 0.2 \\
\hline 350.01 & 14.01 & 214.9 & 0.3 & 499.91 & 41.93 & 341.2 & 0.3 \\
\hline 350.00 & 16.64 & 247.1 & 0.3 & 499.90 & 56.44 & 398.2 & 0.3 \\
\hline 350.03 & 24.18 & 324.3 & 0.3 & 499.89 & 71.16 & 449.1 & 0.3 \\
\hline 350.02 & 31.01 & 375.6 & 0.3 & 499.87 & 83.72 & 488.8 & 0.4 \\
\hline
\end{tabular}

${ }^{\text {a }} U_{w}$ is the expanded uncertainty of speed of sound at a confidence level of $95 \%(k=2)$, composed of standard uncertainties of temperature $u_{T}=0.02 \mathrm{~K}$, pressure $u_{p}: 0.002$ $\mathrm{MPa}$ for $p<10 \mathrm{MPa}$ and $0.02 \mathrm{MPa}$ for $p<100 \mathrm{MPa}$, time $u_{\Delta t}=0.002 \mu \mathrm{s}$ and path length $u_{\Delta l}=7 \mu \mathrm{m}$. 


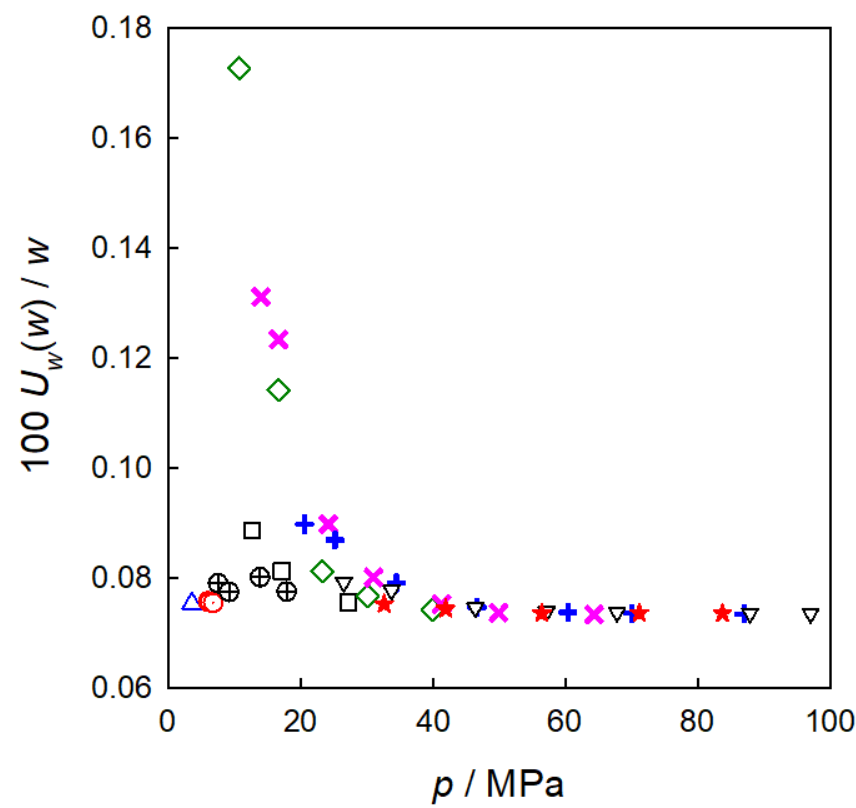

Figure 7: Relative expanded uncertainty for the present speed of sound measurements as a function of pressure: $217 \mathrm{~K} \triangle, 229 \mathrm{~K} \odot, 253 \mathrm{~K} \oplus, 270 \mathrm{~K} \square, 300 \mathrm{~K} \diamond, 350 \mathrm{~K} \times, 400 \mathrm{~K}+, 450$ $\mathrm{K} \nabla, 500 \mathrm{~K} \star$.

of sound measurement of xenon at a typical state point, i.e. $T=349.96 \mathrm{~K}$ and $p=41.320 \mathrm{MPa}$, is provided in Table 4. The largest contribution to the uncertainty budget was due to length calibration, which also includes the reproducibility of the data.

The relative expanded uncertainty for the entire measured range is below $0.1 \%$, except for four data points at low pressures of the isotherms $300 \mathrm{~K}$ and $350 \mathrm{~K}$, cf. Figure 7. The uncertainties are high at these state points because they are approaching the critical point.

The absolute speed of sound of xenon as a function of pressure is presented for different isotherms in Figure 8 (a). It was measured along nine isotherms, where the lowest pressure was chosen depending on quality of the echoes. At low pressures, the speed of sound changes rapidly for temperatures $300 \mathrm{~K}$ and $350 \mathrm{~K}$ because of the proximity of these states to the critical point. In the 
Table 4: Detailed uncertainty budget for the speed of sound of xenon.

\begin{tabular}{cccccc}
\hline \multirow{2}{*}{ source } & type & $\begin{array}{l}\text { measuring } \\
\text { range }\end{array}$ & $\begin{array}{l}\text { standard } \\
\text { uncertainty }\end{array}$ & $\begin{array}{l}\text { speed of sound } \\
\text { derivative }\end{array}$ & $\begin{array}{c}\text { relative expanded } \\
\text { uncertainty }^{\mathrm{a}}\end{array}$ \\
\hline temperature & PT-25 & $84-693 \mathrm{~K}$ & $0.02 \mathrm{~K}$ & $1.2 \mathrm{~m} \mathrm{~s}^{-1} \mathrm{~K}^{-1}$ & $0.023 \%$ \\
pressure & $\begin{array}{c}\text { Keller-PAA-33X } \\
\text { Keller-PAA-33X }\end{array}$ & $<10 \mathrm{MPa}$ & $0.002 \mathrm{MPa}$ & $0.51 \mathrm{~m} \mathrm{~s}^{-1} \mathrm{MPa}^{-1}$ & $0.011 \%$ \\
time & $\begin{array}{c}<100 \mathrm{MPa} \\
\text { Handyscope }\end{array}$ & - & $0.01-0.02 \mathrm{MPa}$ & & $0.009 \%$ \\
path length & HS5 & - & $7 \mu \mathrm{m}$ & $2.2 \cdot 10^{4} \mathrm{~s}^{-1}$ & $0.070 \%$ \\
\hline
\end{tabular}

${ }^{\text {a }}$ Uncertainty value at a typical state point $T=349.96 \mathrm{~K}$ and $p=41.320 \mathrm{MPa}$ for the present speed of sound measurement of xenon.

supercritical region, it increases more moderately with rising pressure. Figure 8 (b) shows a deviation plot analyzing the present speed of sound data on the basis of the equation of state by Lemmon and Span 2 that has a stated uncertainty of $1 \%$ for the speed of sound. All measured state points agree within almost $1.1 \%$. However, it should be noted that the present data systematically diverge from the equation of state at elevated pressures, where the speed of sound was measured with a high accuracy, i.e. $U_{w} \leqslant 0.1 \%$, cf. Figure 7 It can thus be concluded that the equation of state should be improved in the liquid and supercritical regions.

A comprehensive comparison of the present speed of sound data with literature values and the equation of state by Lemmon and Span 2] is presented in Figure 9. It is evident that for the $217 \mathrm{~K}$ and $229 \mathrm{~K}$ isotherms, the present data are in a good agreement with the equation of state as well as the experimental data by Lim et al. 22] and Baidakov et al.24] under an experimental uncertainty of $0.1 \mathrm{~m} \mathrm{~s}^{-1}$ for each. These authors have measured the speed of sound of xenon starting from its vapor pressure up to a maximum of $4 \mathrm{MPa}$ and $6.6 \mathrm{MPa}$, respectively. In the vicinity to their maximum measured pressure, data by Lim et al. 22. systematically approach the present data, which can be seen most clearly for the $229 \mathrm{~K}$ isotherm. Data by Baidakov et al. 24] validate the present results at a state point of $270 \mathrm{~K}$ and $3.8 \mathrm{MPa}$. The majority of 


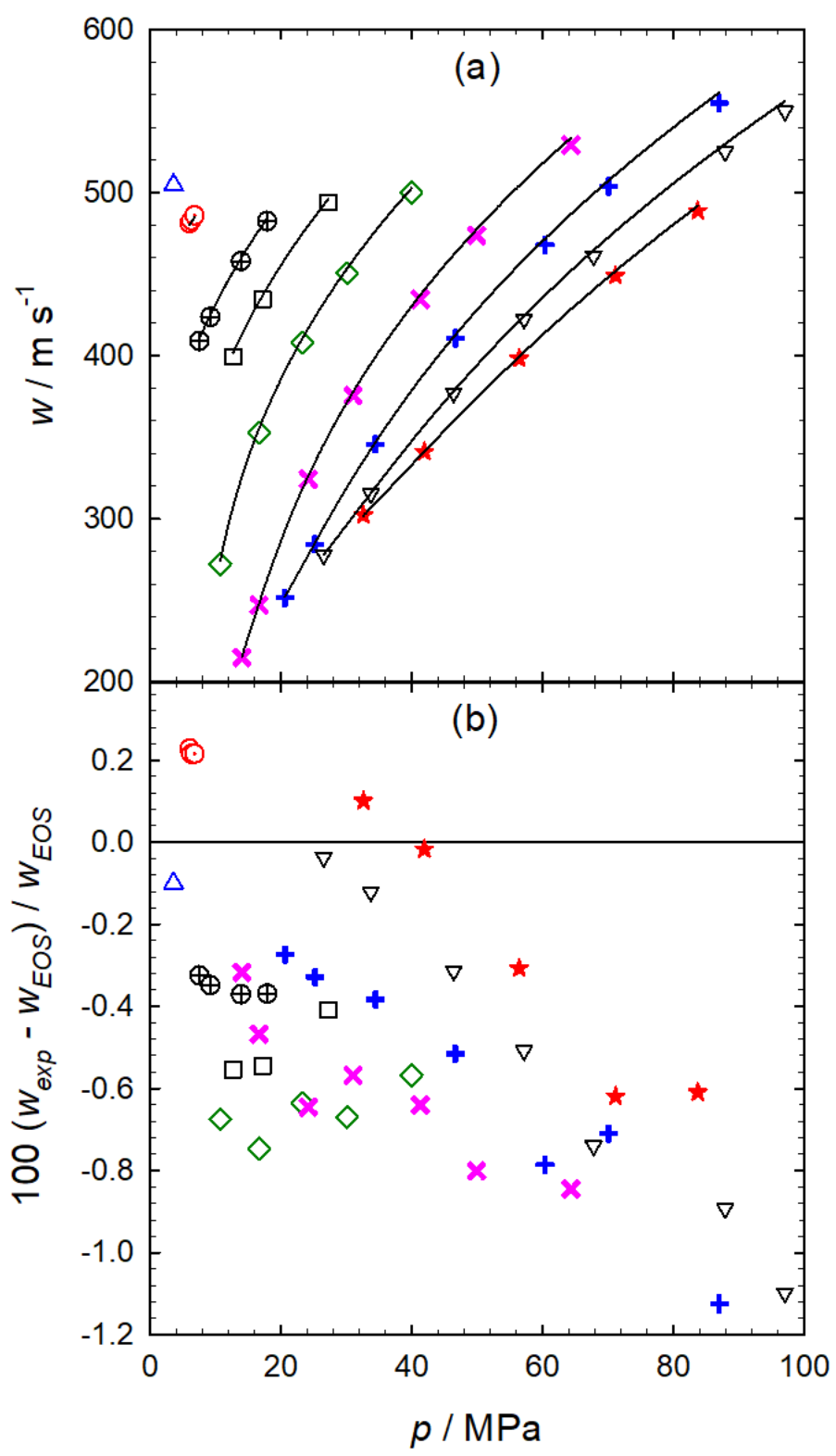

Figure 8: Speed of sound of xenon (a) and deviation of the present data from the equation of state by Lemmon and Span 2] (b): $217 \mathrm{~K} \triangle, 229 \mathrm{~K} \odot, 253 \mathrm{~K} \oplus, 270 \mathrm{~K} \square, 300 \mathrm{~K} \diamond, 350 \mathrm{~K}$ $\times, 400 \mathrm{~K}+, 450 \mathrm{~K} \nabla, 500 \mathrm{~K} \star$. 
the authors has measured the speed of sound along the saturation line only, e.g. Aziz et al. 21, Blagoi et al. 20, and Hurly et al.23. The latter two data sets have a somewhat better consistency with the equation of state, exhibiting a maximum deviation of $0.3 \%$ and $0.7 \%$, respectively. However, data by Aziz et al. 21] show a large scatter of up to $3 \%$ around the equation of state. Only two data sets were reported for the supercritical region by Vidal et al. 26] and Pitaevskaya et al. 25. It should be noted that Vidal et al. have measured nine state points along the isotherm $298 \mathrm{~K}$ with experimental uncertainty of $0.2 \mathrm{~m}$ $215 \mathrm{~S}^{-1}$, but their data exhibit a large scatter with a maximum deviation of about $8 \%$ from the equation of state. The data by Pitaevskaya et al. cover wide spans of temperature and pressure with an experimental uncertainty of $0.5 \mathrm{~m} \mathrm{~s}^{-1}$. However, their data deviate by of up to $6.5 \%$ from the equation of state and even more from the present experimental results, cf. Figure 9.

\subsection{Lennard-Jones potential}

All thermodynamic properties can be obtained from molecular simulation based on a force field, but the results are entirely dependent on quality of the employed model. [36] The Lennard-Jones (LJ) potential model describes the interaction between two spherical molecules located at a distance $r$

$$
u_{L J}(r)=4 \varepsilon\left[\left(\frac{\sigma}{r}\right)^{12}-\left(\frac{\sigma}{r}\right)^{6}\right],
$$

where $\varepsilon$ and $\sigma$ are the energy and size parameters. The truncated and shifted version of the Lennard-Jones (LJTS) potential

$$
u_{L J T S}(r)=\left\{\begin{array}{ll}
u_{L J}(r)-u_{L J}\left(r=r_{c}\right) & \text { for } r \leqslant r_{c} \\
0 & \text { for } r>r_{c}
\end{array},\right.
$$

is a common modification that artificially eliminates interactions beyond the cut-off radius $r_{c}=2.5 \sigma$. 18

The LJ and LJTS potential model parameters reported by Rutkai et al. 18] and Vrabec et al. 37. along with the respective Helmholtz energy equations of 


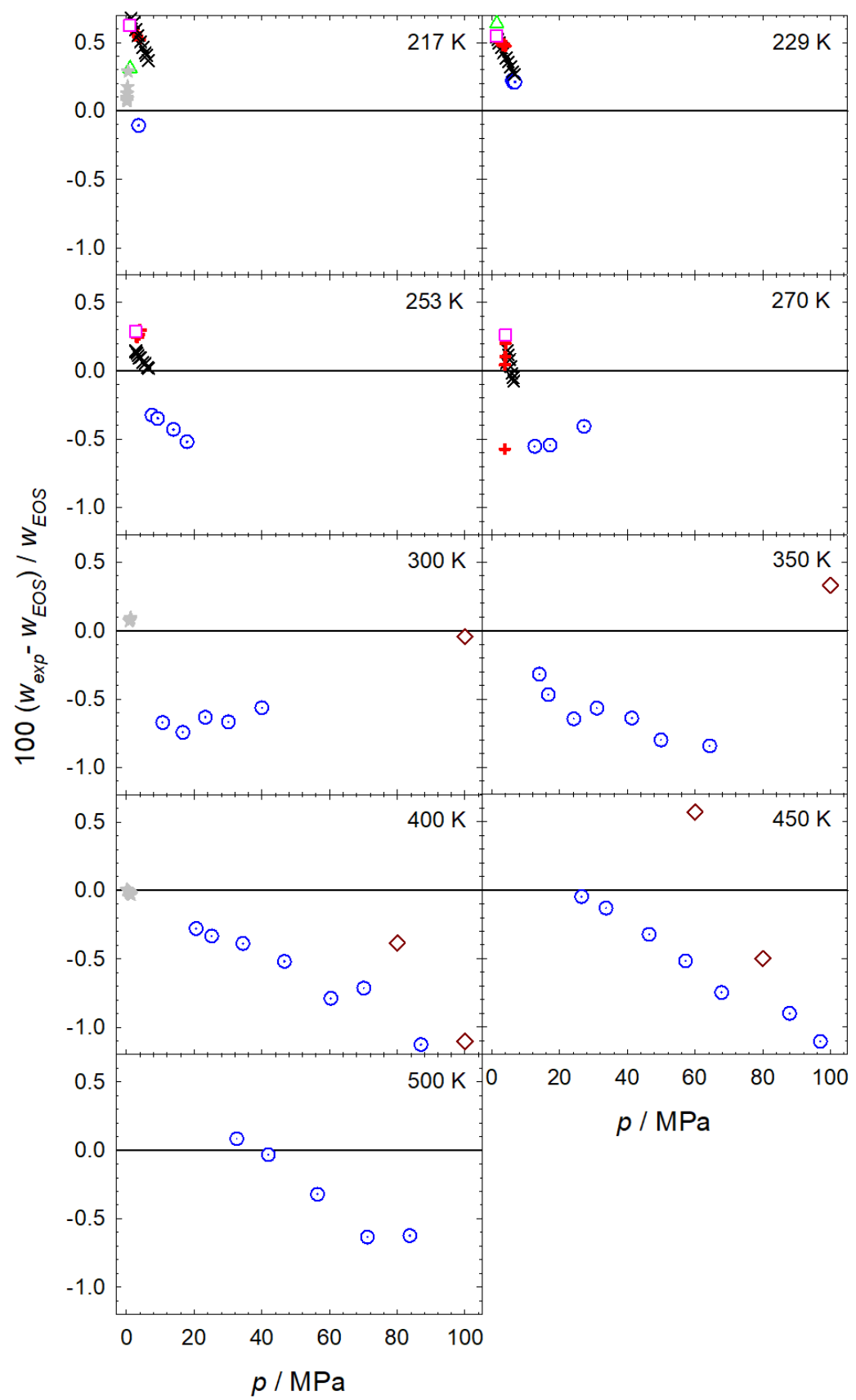

Figure 9: Deviation of the experimental data for xenon from the Helmholtz energy equation of state by Lemmon and Span 2]: this work $\odot$; Blagoi et al. 20] $\triangle$, Aziz et al. 21] $\square, \operatorname{Lim}$ et al. 22 $\times$, Pitaevskaya et al. 25] $\diamond$, Baidakov et al. 24] + , Hurly et al. 23. $\star$. 
state by Thol et al. 38, 39] were taken to predict the speed of sound of xenon.

Temperature, pressure and speed of sound were transformed into reduced units

$$
\begin{gathered}
T^{*}=\frac{k_{B} T}{\varepsilon}, \\
p^{*}=\frac{p \sigma^{3}}{\varepsilon}, \\
w^{*}=w \sqrt{\frac{m}{\varepsilon}} .
\end{gathered}
$$

Therein, $k_{B}$ is the Boltzmann constant and $m=131.29 \mathrm{~g} \mathrm{~mol}^{-1}$ the molecular mass of xenon. The predicted speed of sound data from the LJ and LJTS parameters show large deviations from the equation of state by Lemmon and Span, cf. Figure 10. Therefore, the parameters $\varepsilon$ and $\sigma$ of these models were optimized to the present speed of sound measurements by a least squares method. Numerical values of these parameters are listed in Table 5 . The absolute average deviation $(\mathrm{AAD})$ of the potential model was calculated for the present number $n=42$ of experimental data points

$$
\mathrm{AAD}=\frac{1}{n} \sum_{i=1}^{n}\left|\frac{w_{\text {data }}-w_{\text {equation }}}{w_{\text {data }}}\right|_{i} .
$$

Relative deviations of the experimental data, equations of state for the LJ 39$]$ and LJTS [38, fluids with the parameters by Rutkai et al. 18, Vrabec et al. 37] and this work, from the Helmholtz energy equation of state by Lemmon and Span 2] are presented in Figure 10

Literature parameters for the LJTS model with an AAD of $2.91 \%$ show a somewhat better performance than the LJ parameters with AAD of $3.80 \%$. The LJ parameters by Rutkai et al. 18, are more consistent with the equation of state for all isotherms at elevated pressures. However, at low pressures deviations are much higher with a maximum deviation of about $6 \%$. At elevated temperatures, i.e. from $400 \mathrm{~K}$ to $500 \mathrm{~K}$, the maximum deviations are about $4 \%$ at low pressures 
Table 5: Energy $\varepsilon$ and size $\sigma$ parameters of the Lennard-Jones potential and its truncated and shifted form, together with the resulting critical properties for xenon.

\begin{tabular}{|c|c|c|c|c|c|c|}
\hline & $\sigma / 10^{-10} \mathrm{~m}$ & $\varepsilon / k_{B} / \mathrm{K}$ & $\mathrm{AAD} / \%$ & $T_{c} / \mathrm{K}$ & $p_{c} / \mathrm{MPa}$ & $\rho_{c} / \mathrm{kg} \mathrm{m}^{-3}$ \\
\hline \multicolumn{7}{|l|}{ Rutkai et al. } \\
\hline LJ & 3.949 & 226.14 & 3.80 & 299 & 6.59 & 1097 \\
\hline \multicolumn{7}{|c|}{ Vrabec et al. 37} \\
\hline LJTS & 3.945 & 265.78 & 2.91 & 287 & 6.04 & 1133 \\
\hline \multicolumn{7}{|l|}{ this work } \\
\hline LJ & 3.882 & 223.47 & 1.14 & 295 & 6.86 & 1156 \\
\hline LJTS & 3.936 & 262.00 & 2.17 & 289 & 6.39 & 1191 \\
\hline experiment 2 ] & & & & 290 & 5.84 & 1103 \\
\hline
\end{tabular}

and the results converge to the reference equation of state at high pressures. Parameters by Vrabec et al. 37] for the LJTS model deviate by up to $6 \%$ from the equation of state for $217 \mathrm{~K}$ and $229 \mathrm{~K}$ isotherms at low pressures. However, the deviations are smaller with an offset of about $2 \%$ for high temperature isotherms, i.e. from $400 \mathrm{~K}$ to $500 \mathrm{~K}$.

The present parameters for the LJ and LJTS models with AAD of 1.14\% and $2.17 \%$, respectively, have a noticeably better performance. At elevated temperatures and pressures, they lead to a very good agreement with the equation of state.

The critical properties for xenon resulting from the equation of state, [2] the present and literature parameters for the LJ and LJTS models are provided numerically in Table 5 . Relative deviations of the vapor pressure $p_{v}$ and saturated liquid density $\rho^{\prime}$ calculated form literature and this work parameters for LJ and LJTS models and the equation of state by Lemmon and Span 2] are presented in Figure 11. Because these parameters were optimized to speed of sound data only, other thermodynamic properties, like vapor pressure and saturated liquid density, were significantly deteriorated. It becomes clear that these simple potential functions are insufficient to describe the intermolecular interactions of xenon with a good overall accuracy of the thermodynamic properties. 


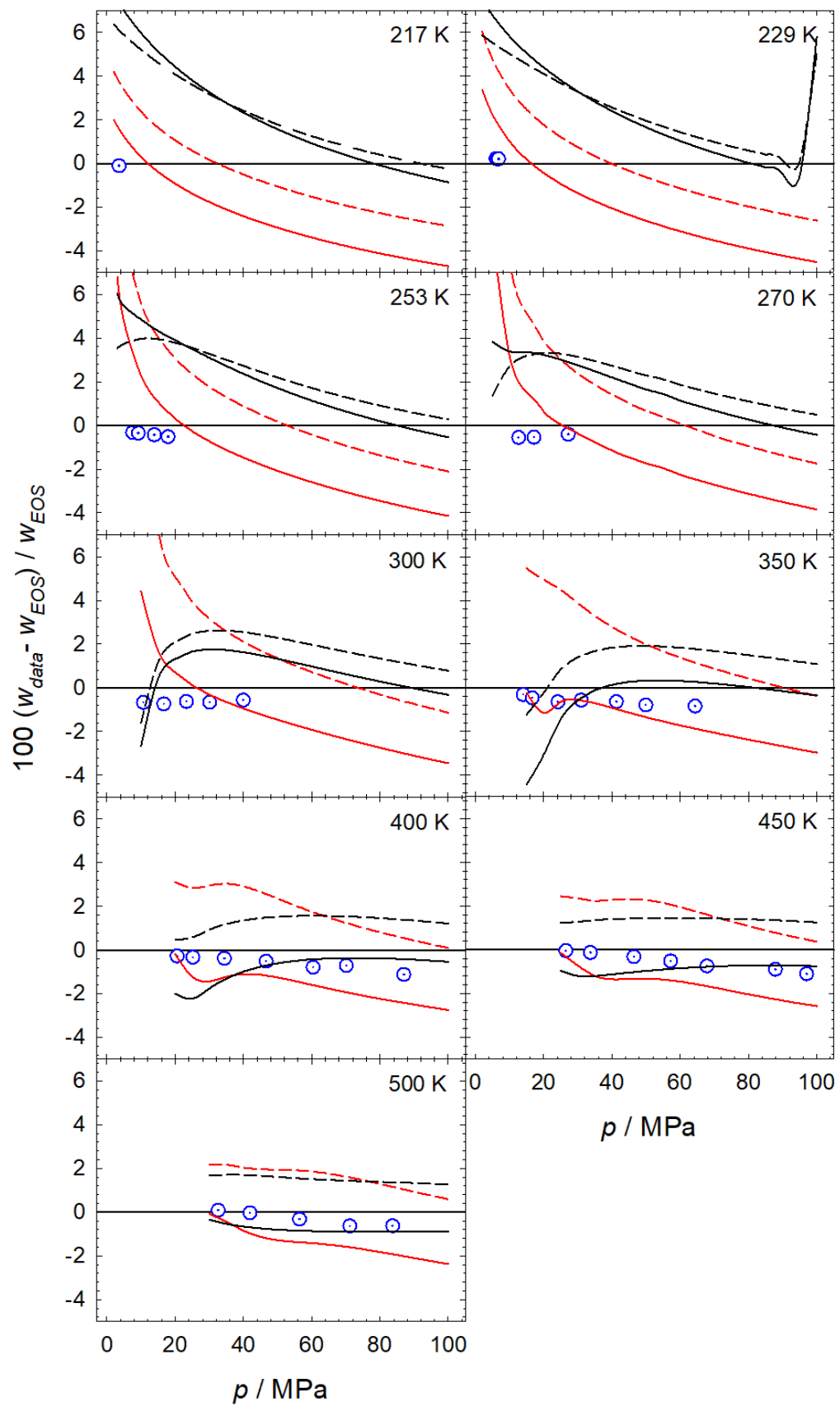

Figure 10: Deviation of data for xenon from the Helmholtz energy equation of state by Lemmon and Span 2]: this work $\odot$; LJ, Rutkai et al. 18] - - -; LJ, this work Vrabec et al.37 - - - ; LTS, this work —. 


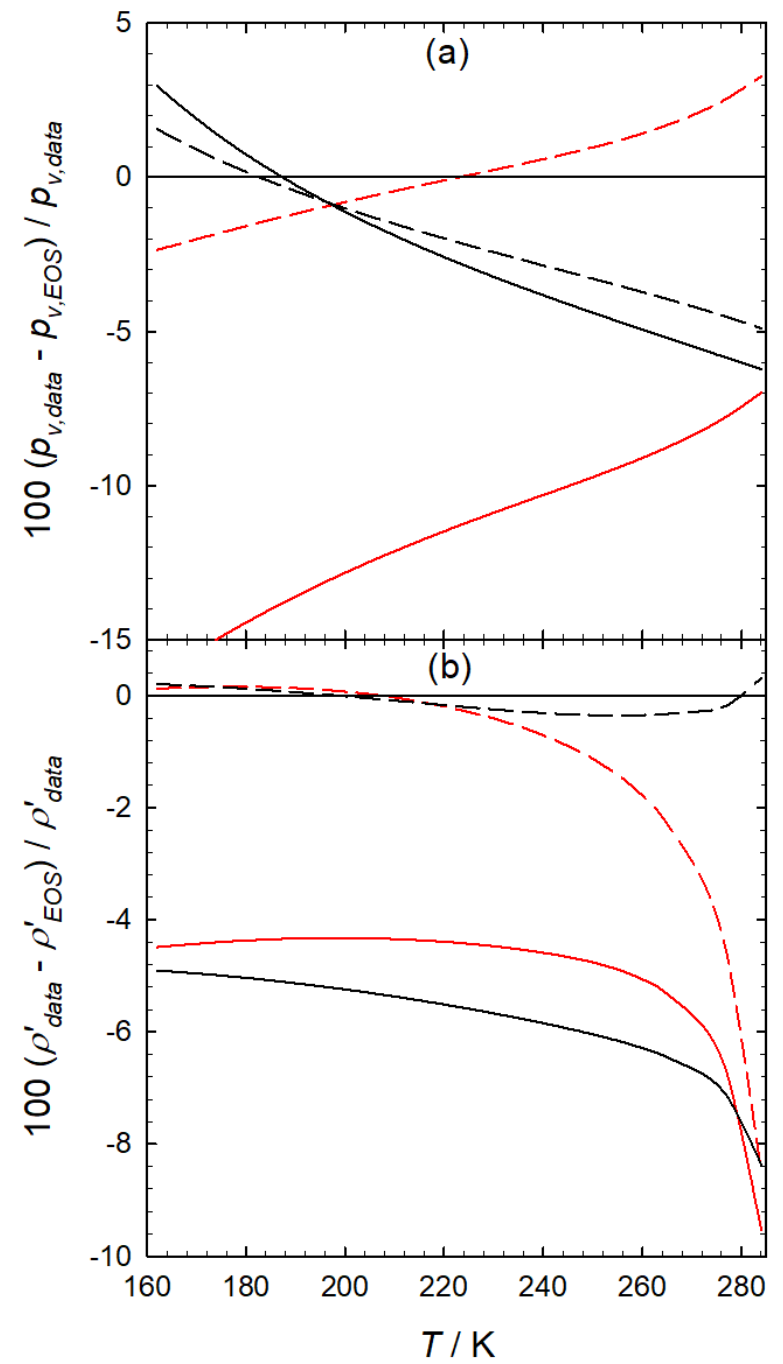

Figure 11: Deviation of the Lennard-Jones model for xenon from the Helmholtz energy equation of state by Lemmon and Span 2 for vapor pressure (a) and saturated liquid density (b): LJ, Rutkai et al. 18 - - -; LJ, this work —; LJTS, Vrabec et al. 37 - - -; LJTS, this work - 


\section{Conclusion}

Xenon is an inert monatomic noble gas with distinct properties that has

thermodynamic speed of sound of xenon was measured with the pulse-echo technique in the liquid and supercritical regions. The data cover a wide temperature range from $220 \mathrm{~K}$ to $500 \mathrm{~K}$ with a pressure of up to $100 \mathrm{MPa}$ and have a maximum expanded uncertainty of $0.17 \%$ at a confidence level of $95 \%$ the Helmholtz energy equation of state by Lemmon and Span with a maximum deviation of about $1.1 \%$. Moreover, the present data were used to optimize the LJ and LJTS potential parameters for xenon. It was found that the LJ (AAD = $1.14 \%)$ and LJTS $(\mathrm{AAD}=2.17 \%)$ parameters from this work lead to a convinc-

\section{5. acknowledgement}

The authors would like to thank Leander Claes from the chair of Elektrische Messtechnik (EMT), Universität Paderborn, for his help during the implementation of the correlation function for the delay in time of flight measurement. The this study.

\section{References}

[1] W. Wagner, A. Pru $\beta$, The IAPWS formulation 1995 for the thermodynamic properties of ordinary water substance for general and scientific use, 
[2] E. W. Lemmon, R. Span, Short fundamental equations of state for 20 industrial fluids, Journal of Chemical \& Engineering Data 51 (2006) 785850.

[3] S. C. Hwang, R. D. Lein, D. A. Morgan, Noble gases, Kirk-Othmer Encyclopedia of Chemical Technology 17 (2000) 343-383.

[4] J. Rajam, Atomic Physics, S. Chand, Delhi, 1966.

[5] E. Aprile, A. I. Bolozdynya, A. E. Bolotnikov, T. Doke, Noble gas detectors, John Wiley \& Sons, Weinheim, 2006.

[6] D. A. Herman, K. G. Unfried, Xenon acquisition strategies for high-power electric propulsion, NASA, Cleveland, 2015.

[7] J. Emsley, Nature's Building Blocks: An A-Z Guide to the Elements, OUP, Oxford, 2011.

[8] F. G. Kerry, Industrial gas handbook: gas separation and purification, CRC press, New York, 2007.

[9] P. Häussinger, R. Glatthaar, W. Rhode, C. Kick, Helmut; Benkmann, J. Weber, H.-J. Wunschel, V. Stenke, E. Leicht, H. Stenger, Noble gases, Ullmann's Encyclopedia of Industrial Chemistry 24 (2000) 391-448.

[10] P. M. Rentzepis, D. C. Douglass, Xenon as a solvent, International Journal of Thermophysics 293 (1981) 165-166.

[11] L. Baudis, Darwin dark matter wimp search with noble liquids, Journal of Physics: Conference Series 375 (2012) 012028.

[12] K. Zona, Innovative engines: Glenn ion propulsion research tames the challenges of 21st century space travel, NASA, Cleveland, 2007.

[13] J. Burke, Twin tracks: the unexpected origins of the modern world, Simon and Schuster, New York, 2003.

[14] D. Mellor, Sound Person's Guide to Video, Focal Press, New Delhi, 2013. 
[15] M. Luhmer, A. Dejaegere, J. Reisse, Interpretation of the solvent effect on the screening constant of xe-129, Magnetic Resonance in Chemistry 27 (1989) 950-952.

[16] J. D. Brazzle, M. R. Dokmeci, C. H. Mastrangelo, Modeling and characterization of sacrificial polysilicon etching using vapor-phase xenon difluoride, in: 17th IEEE International Conference on Micro Electro Mechanical Systems. Maastricht MEMS 2004 Technical Digest, IEEE, 2004, pp. 737-740.

[17] M. A. Javed, E. Baumhögger, J. Vrabec, Thermodynamic speed of sound data for liquid and supercritical alcohols, Journal of Chemical \& Engineering Data 64 (2019) 1035-1044.

[18] G. Rutkai, M. Thol, R. Span, J. Vrabec, How well does the lennardjones potential represent the thermodynamic properties of noble gases?, Molecular Physics 115 (2017) 1104-1121.

[19] M. Thol, M. A. Javed, E. Baumhögger, R. Span, J. Vrabec, Thermodynamic properties of dodecamethylpentasiloxane, tetradecamethylhexasiloxane, and decamethylcyclopentasiloxane, Industrial \& Engineering Chemistry Research 58 (2019) 9617-9635.

[20] Y. P. Blagoi, A. Butko, M. SA, V. Yakuba, Velocity of sound in liquid krypton, xenon and methane, Russian Journal of Physical Chemistry 41 (1967) 1699-1702.

[21] R. Aziz, D. Bowman, C. Lim, Sound velocity in the inert gas liquids and the law of corresponding states, Canadian Journal of Chemistry 45 (1967) 2079-2086.

[22] C. Lim, D. Bowman, R. A. Aziz, Velocity of sound isotherms in liquid krypton and xenon, Canadian Journal of Chemistry 46 (1968) 3477-3482.

[23] J. J. Hurly, J. W. Schmidt, S. Boyes, M. R. Moldover, Virial equation of state of helium, xenon, and helium-xenon mixtures from speed-of-sound 
and burnett p $\rho$ t measurements, International Journal of Thermophysics 18 (1997) 579-634.

[24] V. Baidakov, A. Kaverin, V. Skripov, Thermodynamic properties of metastable liquefied inert gases: Part 1. the ultrasonic speed in superheated krypton and xenon, Physica B 128 (1985) 207-217.

[25] L. Pitaevskaya, A. Bilevich, B. Kanishev, The rate of propagation of ultrasound in compressed xenon, Russian Journal of Physical Chemistry 49 (1975) 1292-1295.

[26] D. Vidal, L. Guengant, M. Lallemand, Vitesse des ultrasons dans les gaz rares sous haute pression a la temperature de 298.15 k, Physica A 96 (1979) $545-560$.

[27] D. Vidal, R. Tufeu, Y. Garrabos, B. Le Neindre, High pressure science and technology, in: High pressure science and technology. Proceedings of the VIIth international AIRAPT Conference. Part I, II. Conference held at Le Creusot, France, 30 July-3 August 1979., Proceedings 1980, pp. 692-698.

[28] S. Ball, J. Trusler, Speed of sound of n-hexane and n-hexadecane at temperatures between 298 and $373 \mathrm{k}$ and pressures up to $100 \mathrm{mpa}$, International Journal of Thermophysics 22 (2001) 427-443.

[29] K. Meier, S. Kabelac, Speed of sound instrument for fluids with pressures up to $100 \mathrm{mpa}$, Review of Scientific Instruments 77 (2006) 123903.

[30] C. W. Lin, J. P. Trusler, The speed of sound and derived thermodynamic properties of pure water at temperatures between (253 and 473) K and at pressures up to $400 \mathrm{MPa}$, The Journal of Chemical Physics 136 (2012) 094511.

[31] V. A. Del Grosso, C. W. Mader, Speed of Sound in Pure Water, The Journal of the Acoustical Society of America 52 (1972) 1442-1446. 
[32] W. Marczak, Water as a standard in the measurements of speed of sound in liquids, The Journal of the Acoustical Society of America 102 (1997) 2776-2779.

[33] K. Fujii, R. Masui, Accurate measurements of the sound velocity in pure water by combining a coherent phase-detection technique and a variable 375 path-length interferometer, The Journal of the Acoustical Society of America 93 (1993) 276-282.

[34] S. Z. Al Ghafri, E. A. Matabishi, J. M. Trusler, E. F. May, P. L. Stanwix, Speed of sound and derived thermodynamic properties of para-xylene at temperatures between (306 and 448) k and at pressures up to $66 \mathrm{mpa}$, The Journal of Chemical Thermodynamics 135 (2019) 369-381.

[35] F. H. Dubberke, E. Baumhögger, J. Vrabec, Burst design and signal processing for the speed of sound measurement of fluids with the pulse-echo technique, Review of Scientific Instruments 86 (2015) 054903.

[36] D. Frenkel, B. Smit, Understanding molecular simulation: from algorithms to applications, Elsevier, Amsterdam, 2001.

[37] J. Vrabec, G. K. Kedia, G. Fuchs, H. Hasse, Comprehensive study of the vapour-liquid coexistence of the truncated and shifted lennard-jones fluid including planar and spherical interface properties, Molecular Physics 104 (2006) 1509-1527.

[38] M. Thol, G. Rutkai, R. Span, J. Vrabec, R. Lustig, Equation of state for the lennard-jones truncated and shifted model fluid, International Journal of Thermophysics 36 (2015) 25-43.

[39] M. Thol, G. Rutkai, A. Köster, R. Lustig, R. Span, J. Vrabec, Equation of state for the lennard-jones fluid, Journal of Physical and Chemical 